\title{
El Turismo Cultural desde la Educación Patrimonial Transcompleja en Venezuela
}

\section{Resumen}

Milagros Elena Rodríguez

Es urgente de acuerdo con las premisas de la transcomplejidad diseñar estrategias que permitan enfrentar en el turismo cultural los riesgos, lo inesperado, lo incierto, $\mathrm{y}$ atender el proceso educativo como aquel lleno de profundas incertidumbres y no de determinismos. La transmetodologia que sustenta el turismo cultural desde la Educación Patrimonial Transcompleja en la presente indagación es el transmétodo la hermenéutica comprensiva, ecosofica y diatopica como construcción teórica. La Educación Patrimonial Transcompleja es el ejercicio educativo que basándose en el asunto patrimonial de un ciudadano comprometido propende una identidad que lo define e identifica con su patrimonio cultural. Se concluye que el turismo cultural sustentado desde la Educación Patrimonial Transcomplejidad constituye un espacio político donde desde la diversidad cultural como el patrimonio cultural universal se establece relaciones de reconocimientos de los países y con ello el respeto por los ciudadanos. Se caracteriza porque que se requiere del trabajo complejizado de diálogos y acuerdos en conjunto entre los diversos actores de los sectores turísticos y culturales, los cultores de las comunidades locales que mediante adecuados procesos de gestión transcompleja, produzcan desarrollos turísticos sanos y equilibrados, atractivos y portadores de políticas comprometidas y una continua formación de gestores culturales. En Venezuela, es deseable la conformación de un sujeto transmoderno en materia de turismo cultural que conyugue a la protección de nuestra cultura, el patrimonio cultural y natural, su salvaguarda; si sometimiento, liberado de las opresiones politiqueras en favor de intereses particulares; ir a un verdadero ejercicio educativo patrimonial en material de una gestión transmoderna y transcompleja.

Palabras clave: turismo cultural, Educación Patrimonial Transcompleja, salvaguarda, transmodernidad.

\section{Abstract}

\section{Cultural Tourism From Transcomplete Patrimonial Education in Venezuela}

It is urgent in accordance with the premises of the transcomplexity to design strategies that allow facing in the cultural tourism the risks, the unexpected, the uncertain, and attend the educational process as that full of deep uncertainties and not of determinisms. The transmetodology that underpins cultural tourism from the Transcomplex Heritage Education in the present investigation is the transmethod the comprehensive, ecosophical and diatopic hermeneutics as a theoretical construction. Transcompleja Patrimonial Education is the educational exercise that, based on the patrimonial issue of a committed citizen, properes an identity that defines it and identifies it with its cultural heritage. It is concluded that the cultural tourism supported by Patrimonial Education Transcomplexity constitutes a political space where from the cultural diversity as the universal cultural patrimony relationships of recognitions of the countries are established and with this respect for the citizens. It is characterized because it requires

a. Pós-Doutora pelo Departamento de Matemáticas da Universidad de Oriente, Cumaná, Estado Sucre, Venezuela. Docente do Departamento de Matemáticas da Universidad de Oriente, Cumaná, Estado Sucre, Venezuela. E-mail: melenamate@hotmail.com 
the complex work of dialogues and agreements between the various actors of the tourism and cultural sectors, the cultores of the local communities that through appropriate processes of transcomplex management produce healthy and balanced tourism developments, attractive and carriers of committed policies and continuous training of cultural managers. In Venezuela, the conformation of a transmodern subject in the field of cultural tourism that brings together the protection of our culture, cultural and natural heritage, its safeguarding is desirable; if submission, freed from political oppression in favor of private interests; go to a true heritage educational exercise in material of a transmodern and trans-complex management.

Keywords: cultural tourism, HeritageEducation Transcomplex, safeguard, transmodernity.

\section{Resumo}

\section{Turismo Cultural da Educação Patrimonial Transcompleta na Venezuela}

É urgente de acordo com as premissas de estratégias de design transcomplejidad para enfrentar os riscos de Turismo Cultural, inesperados, incertos, e abordar o processo educacional como um cheio de profundaincerteza e não determinismo.Atransmetodologia que sustenta o turismo cultural a partir da Educação Patrimonial Transcomplexo na presente investigação é a metamorfose transmódromo da hermenêutica compreensiva, ecosófica e diatópica como construção teórica. Transcompleja Educação Patrimonial é o exercício educativo que, baseado na questão patrimonial de um cidadão comprometido, se apropria de uma identidade que o define e o identifica com sua herança cultural. Conclui-se que o turismo cultural apoiado pela Transcomplexidade da Educação Patrimonial constitui um espaço político onde a partir da diversidade cultural como o patrimônio cultural universal se estabelecem relações de reconhecimentos dos países e com este respeito pelos cidadãos. Caracteriza-se porque exige diálogos mais complexos de trabalho e acordos conjuntos entre as várias partes interessadas no turismo e setores culturais, os cultistas das comunidades locais através de processos adequados de gestão transcomplex, produzem o desenvolvimento do turismo saudável e equilibrada, atraente e operadoras de políticas comprometidas e treinamento contínuo de gestores culturais. Na Venezuela, a conformação de um sujeito transmoderno no campo do turismo cultural que reúne a proteção de nossa cultura, patrimônio cultural e natural, é desejável sua salvaguarda; se submissão, livre de opressão política em favor de interesses privados; ir a um verdadeiro exercício educacional de patrimônio em material de uma gestão transmoderna e transcomplexa.

Palavras-chave: turismo cultural, Transcomplexo da Educação Patrimonial, salvaguarda, transmodernidade.

\section{RIZOMA: UN ACERCAMIENTO AL TEMA}

La Educación Patrimonial Transcompleja se muestra como un dinámico elemento de ciudadanía e inclusión social de la cultura autóctona. Donde los espacios de independencia y autodeterminación venezolano están en consonancia con su cultura; ejercicio educativo que es atravesado pon la cotidianidad y los saberes soterrados; la historicidad forma parte de la vida del ciudadano y la conformación de su identidad; hacia la defensa del patrimonio más universal: la tierra.

El turismo cultural en el mundo es un novedoso promotor de la cultura. Es un acercamiento al reconocimiento de lo nuestro; pero que en el cuidado y 
promoción de la cultura autóctona se establece una mirada cuidadosa, sobre todo si la cultura a promover es desde una mirada transmoderna y transcompleja. No dejando de lado la diversidad cultural que en muchos casos provienen de procesos de transculturización y aculturización. En general, de acuerdo con Nava y Castillo (2017) el turismo es un fenómeno que no ha sido reinterpretado, sino estudiado de una manera positivista, bajo el paradigma reduccionista y sistematizada por varias ciencias que lo han transfigurado en una disciplina dependiente de las grandes ciencias, de conocimientos científicos y los saberes soterrados han quedado relejados en su estudio.

Según Luzardo (2014) si bien en Venezuela el patrimonio cultural se encuentra representado por una amplia gama de ciudades y comunidades con recursos y potencial turístico, los cuales en su mayoría se encuentran localizados en los cascos históricos como referencia urbanística y arquitectónica del siglos pasados la mayoría edificados con la invasión al continente, no se han establecido políticas que permitan integrar los diversos sectores, tanto públicos como privados, relacionados con la cultura y el turismo que vayan en concordancia con el desarrollo sostenible de los recursos patrimoniales, su promoción y puesta en valor; en ello mucho menos la cultura autóctona, esta lleva la peor parte en el turismo cultural. Nos preguntamos: ¿Estamos formados para promover nuestra cultura verdaderamente y su salvaguarda?

Para volver a esta pregunta incisiva es bueno clarificar el proyecto transmoderno y el transparadigma transcomplejo. Y más delante de que se trata la Educación Patrimonial Transcompleja y algunos puntos del estado del arte del turismo cultural en Venezuela. Además de, la profunda relación compleja entre turismo y cultura, o el turismo de la cultura.

El proyecto transmoderno, en contraposición con la hegemonía de la modernidad colonizada impuesta, es una posibilidad de mentes descolonizadas, no son pocas las razones sustentadas en Enrique Dussel de como en la transmodernidad encuentra el asidero necesario para la realización de dicha investigación; sigue afirmando Dussel (1992, p.162) “este proyecto transmoderno será también fruto de un diálogo entre culturas". Es aquí donde tiene sentido la diversidad cultural, el turismo cultural en pleno; sin soslayarlos; sin incisiones; pero cobrando preeminencia por lo nuestro autóctono.

En un espacio libre de ataduras, en la transmodernidad consigue su plena realización la transcomplejidad; esta manera de pensar y de constituir una investigación sólo es posible en la transcomplejidad donde la complejidad y transdiciplinariedad constituyen el transparadigma. González (2010, p.13) afirma que "este pensamiento transcomplejo ha construido conceptos científicos educativos muy importantes como aula mente social, emergentes educativos, metacomplejidad, deconstrucción educativa y complejidades curriculares". El hecho de mirar desde su complejidad, descolonización y ecología de los saberes a la Educación Patrimonial es de un especial valor e interés en la vida y rescate de la verdadera identidad descolonizada de los ciudadanos de Venezuela; pues el vivir desde la consciencia y el orgullo de lo que somos cobra preeminencia en el rescate de nuestra cultura en un proceso de globalización en todos los niveles y mostrar dicha realidad en el turismo cultural.

De acuerdo con Rodríguez (2018) la educación patrimonial, se ha delineado desde los diseños curriculares, las leyes orgánicas de educación, las constituciones 
venezolanas, y convenios internacionales, vinculada al proyecto de nación propuesta desde el modelo económico imperante, con la finalidad de definir la identidad de los venezolanos, y las expresiones de ciudadanía. En general, forma un docente reduccionista, limitado a los conocimientos de la disciplina, acrítico. Un individuo a histórico, cuya vida escolar solo había tenido sentido en sus primeros niveles, el leer, escribir y contar. En las universidades se enseñaba filosofía e idiomas, pero aisladas de las otras disciplinas. Pretendía la formación de un ciudadano técnico, exclusivamente para el trabajo.

En contraposición con dicha problemática, surge la Educación Patrimonial Transcompleja en Rodríguez (2017a). Se construyó con las ideas especial de González (2010; p.116) quien afirma que "la educación transcompleja permite justamente la reflexión humana como centro de comprensión en el accionar humano". No es una educación reproductiva o materialista sino una educación social donde los seres humanos contrarios armonizan y los semejantes se complementan.

En la educación patrimonial en general parte de la premisa de Morín (1998) que afirma es urgente derribar las murallas del conocimiento fragmentado entre las disciplinas y así buscar la manera de volver a unirlo mediante diadas y hacer visibles las conexiones existentes; es más reinventarse las que no son tan evidentes; en este caso quiere ver el conocimiento de los saberes patrimoniales inmiscuidos y transversalizador por los demás saberes, es la complejidad de los conocimientos en general; romper las incisiones unidisciplinares, las fronteras del conocimiento que tanto daño han hecho; de la misma manera las barreras entre los saberes científicos y los soterrados. Es urgente Moreno (2016, p.65) "generar una educación patrimonial basado en el pensamiento complejo, atendiendo a la necesidad de considerar a los patrimonios como un concepto complejo".

Es urgente de acuerdo con las premisas de la complejidad diseñar estrategias que permitan enfrentar en el turismo cultural los riesgos, lo inesperado, lo incierto, y atender el proceso educativo como aquel lleno de profundas incertidumbres y no de determinismos. También parte de la acepción de antecedentes a esta investigación donde clama por evitar que el patrimonio cultural muera en la vida social de los ciudadanos, como la define García (2016, p.41) “la educación patrimonial es una vía para construir redes cognitivas y afectivas con el patrimonio y promover la participación de las comunidades locales en la valoración de su patrimonio material e inmaterial"; le turismo cultural es un espacio propicio para la promoción de nuestros patrimonio cultural, natural, e histórico.

La Educación Patrimonial Transcompleja es el ejercicio educativo, que tiene por base el asunto patrimonial, que es esencialmente político y se muestra como un emprendedor componente de la ciudadanía e inclusión social, tal como lo avala Rodríguez (2017a). Desde allí se abren miradas otras, a otros horizontes de conocimiento, de los saberes patrimoniales que hoy están cerrados, satanizados.

Desde la conciencia cultural categoría que se explorará en su significancia en el turismo cultural se aspira el reconocimiento de nuestra cultura, del patrimonio cultural y de cómo desde éste se recobran magnificencias que permitan una Educación Patrimonial, abierta compleja y profundamente transdiciplinar. Descolonizar implica en este caso desplazarse de la universidad a la pluriversidad; es transformar imposiciones y formas de hacer turismo cultural.

De acuerdo con Abreu y Lunar (2008) el turismo cultural Venezolano, en un sentido amplio ayuda a afianzar la interacción entre la naturaleza y la cultura 
de un lugar o región, para llegar a constituir una oferta atractiva, en este sentido, el desarrollo de la actividad turística en Venezuela, ha estado determinada por la diversidad ambiental que posee, constituyendo esto su patrimonio natural. Además de contar con un patrimonio cultural derivado de la aculturización, transculturización de diferentes culturas que a través de la historia llegaron a imponerse y la cultura autóctona que niega a morirse.

De acuerdo Luzardo (2014, p.2) con el turismo cultural presenta una "estrecha y dinámica interacción con los contenidos y valores culturales del patrimonio cultural, que ofrece una amplia gama de oportunidades y posibilidades de difusión y pertenencia, al conocer los deseos y expectativas tanto de los visitantes como de las comunidades residentes". Por ello patrimonio cultural y bienes culturales son conocidos en el turismo cultural.

En especial, de acuerdo con Campodónico y Chalar (2013, p.48) "el turismo es un fenómeno integral y multidimensional, resultado de la relación e interrelación de múltiples actores en diversos contextos espacio-temporales", así la consideración compleja y transdiciplinar del turismo es menester de estudiar. Especialmente en una mirada descolonizada y de consideración antropoética y que la Educación Patrimonial Transcompleja da un viraje a la significancia del turismo cultural en particular. Turismo cultural, cultura, patrimonio cultural, Educación Patrimonial Transcompleja se retroactuan y alimentan en la dialéctica que acá se establece. Todo ello indica la cumplejidad desde la significancia de la palabra turismo, un mundo extremadamente complejo, como toda realidad es compleja, mucho más cuando la realidad a conocer es social; según Muñoz (2014).

El grado de complejidad en general entre turismo y cultura, la conjunción implica crear espacios de interacción donde los turistas y las comunidades puedan dialogar respecto del universo de significaciones y concepciones del mundo de la cultura, del patrimonio cultural a la cual se acercan. Hacer turismo cultural es visitar otra comunidad en cuanto con el reconocimiento de su cultura; esto es, desde luego teniendo en cuenta que el turista no es neutro e interactúa y se identifica también desde la cultura de donde él es portador, son los sistemas simbólicos que forman parte de la experiencia que hace del turismo una práctica estética.

Por ello, el enfoque desde la Educación Patrimonial Transcompleja al turismo cultural es de vital importancia. El turismo forma parte de los procesos que contribuyen a la construcción, reconstrucción de la cultura de los pueblos, en donde las denominadas culturas minoritarias y apartadas deben participar. El turismo cultural, es también un proceso histórico y social que instituye relaciones de poder que se hacen visibles en los y de reconocerse como aquel muy disímil en su propia cultural, la del visitante. En Latinoamérica y el Caribe, por ejemplo los turistas se pueden llegar a reconocer como hermanos, como participes de culturas originarias parecidas, pero con especial bella de gentileza.

La formación de ciudadanos en cuanto a gestores de su cultura, conocedores de ellas. Y la conciencia especial de promover nuestra cultura autóctona la olvidada. Es parte de la investigación, aún no como centro la formación en turismo cultural desde la Educación Patrimonial Transcompleja. En lo que se sigue se describe como es la parte transmetodologica de la presente indagación, trans que significa más allá. 


\section{RIZOMA TRANSMETODOLOGICO}

En primer lugar aquí se clarifica la utilización y significancia de la palabra rizoma. Que se usa de manera envolvente en los subtítulos de la presente investigación tiene una insinuación circundante, atiende a Deleuze y Guattari (1994) en el que de manera compleja puede ser conectada con cualquier otro los razonamientos y ramas que constituyen la disposición; es una anti-genealogía que rompe con las estructuras estáticas divisorias de presentar las investigaciones en las que las partes se dividen indisolublemente en un ir si un venir. Acá la organización no responde a ningún modelo estructural o generativo.

Es ir con Deleuze y Guattari (1994, p.20) a significancias investigativas semejantes con un rizoma que no "empieza ni acaba, siempre está en el medio, entre las cosas, inter-ser, intermezzo (...) el árbol es filiación, pero el rizoma tiene como tejido (...) En esta conjunción hay fuerza suficiente para sacudir y desenraizar el verbo ser". Se usa por primera vez en investigación doctoral inédita, donde se crea la Educación Patrimonial Transcompleja, la palabra rizoma para estructuras de trabajos de investigación en Rodríguez (2017a). El rompimiento con la tradicionalidad modernista de las indagaciones denotadas en las estructuras tradicionalistas de las investigaciones cualitativas o cuantitativas.

La transmetodologia que sustenta el turismo cultural desde la Educación Patrimonial Transcompleja en la presente indagación es el transmétodo la hermenéutica comprensiva, ecosofica y diatopica como construcción teórica, conjugado y complejizado con el ejercicio comprensivo, ecosofico y diatopico. Que utiliza da manera inédita en Rodríguez (2017a). La tarea de dicho hermenéutica no es explicar lo exterior, aquello en lo que la experiencia se expresa, sino comprender la interioridad de la que ha nacido lo relativo a las categorías de las indagaciones; a todos sus saberes; en este caso la hermenéutica comprensiva le permite a la investigador, según Rodríguez (2017a) interpelar los territorios temáticos del conocimiento, la imaginación creadora, la actitud transvisionaria, la irreverencia frente a lo conocido, los modos de interrogar la realidad, la criticidad en el hermeneuta (la autora), la libertad de pensamiento entre otras.

En cuanto al carácter complejo de la hermenéutica anidada por la ecosofía, Pupo (2017, p.10) afirma que "la ecosofía no renuncia ni a la ciencia ni a la tecnología, simplemente subraya que el uso que hacemos de ellas no satisface las necesidades humanas básicas como un trabajo con sentido en un ambiente con sentido". No ha de olvidarse que justamente la ciencia y tecnología es anidada por los saberes soterrados en la complejidad; no es motivo de dicho transparadigma desmitificar la cientificidad; lo que si asume es que esta no es suficiente.

La ecosofía, en los estudios de unos de los pioneros Félix Guattari y otros filósofos humanistas que unen la filosofía, el arte, la ciencia y toda producción humana a la tierra, deviene, a una nueva inteligencia del oikos, la casa del mundo y a una renovación práctica del ethos, los modos de habitar. Pupo $(2017$, p.10) afirma que "la hermenéutica ecosófica, una pragmática existencial cósmica, crítica cuyas interpretaciones siguen una lógica plural con sentido cultural y complejo, pero al mismo tiempo, comprometida con el destino del hombre y la Tierra".

En tanto que Balza (2016, p.44) afirma que la hermenéutica ecosofica asume una configuración ética y "comprensiva de las relaciones entre los seres humanos en su interacción cultural con el planeta tierra, lo cual deviene en una necesaria 
transformación de la conciencia para integrarnos a la unidad de la vida, cuya lógica es la dialógica comprensiva". En ese sentido la transmodernidad en plena consideración respalda el carácter ecosófico de las investigaciones transcomplejas. Pupo (2014) habla del carácter ecosófico en la reflexión sobre nuestras costumbres, el cuidado de la tierra como el patrimonio natural más grande, también la relación ciencias y los saberes provenientes de la cultura; como fue el caso de la primera transmetodología transcompleja en patrimonio cultural creada por Rodríguez (2017a).

Ratifica Pupo (2017, p.5) que para la formación de una conciencia ecológica mediante la reconceptualización de la noción de cultura y el establecimiento de sus vínculos esenciales con la naturaleza, "la vía propuesta es la hermenéutica ecosófica, de manera que la conciencia ecológica a que se arribe, nos permita comprender la naturaleza como parte del espíritu y el cuerpo de lo humano". Esta conciencia ecológica tiene total pertinencia en el turismo cultural a sustentar y la antropoética, la ética del género humano es generadora de esa conciencia ecológica.

De la hermenéutica en cuestión como transmétodo, afirma Santos (2002, p.70) que su carácter diatópico consiste en "elevar la conciencia de la incompletud a su máximo posible participando en el diálogo, como si se estuviera con un pie en una cultura y el otro en la restante. Aquí yace su carácter diatópico". Es así como, desde este carácter se respeta la diversidad cultural, por ejemplo en estudios de cultura y donde quiera que se deban versar saberes científicos y saberes soterrados; tal cual Santos (1998, p.30) respalda el hecho de que la hermenéutica diatópica no sólo requiere "un tipo de conocimiento diferente, sino también un proceso diferente de creación de conocimiento. Requiere la creación de un saber colectivo y participativo basado en intercambios cognitivos y emotivos iguales, un conocimiento como emancipación, más que un conocimiento como regulación". Todos estos conocimientos y saberes son compartidos en la práctica del turismo cultural.

Desde luego, que desarrollando el carácter diatopico no va reñido con el ecosofico; por el contrario uno explica y respalda al otro y es de alta importancia en la consideración de la complejidad de las crisis mundiales desplegar una hermenéutica ecosófica, una conciencia ecológica que propicie el acaecimiento y aseveración de una cultura ecosófica, donde el ser humano vea la naturaleza integrada parte de su cuerpo y de su espíritu. Una propuesta que se lleva a cabo en el turismo cultural como reconocimiento de lo nuestro y promoción de los saberes a ser reconocidos para habitar en el planeta sin destruirlo, su preservación.

Una hermenéutica ecosófica, siguiendo el carácter integrador, cultural y complejo que la caracteriza puede aportar mucho a la interpretación constructiva y transformadora de una moral, fundada en el bien común, la justicia, la libertad y la virtud del ser humano; son palabras de Pupo (2017, p.20) "la misión de la hermenéutica ecosófica, por estar comprometida con el destino de nuestro planeta y de la vida que la habita, (...), capaz de propiciar la comunicación y la comprensión de los seres humanos sobre nuevas bases cosmovisivas". La hermenéutica ecosófica interpreta la conducta moral, sus ideas, principios y valores que norman o dan cauce al quehacer humano en sus mundos de las instituciones educativas, del mundo de la vida, del desempeño profesional, desde una perspectiva planetaria, sin perder los contextos socioculturales específicos.

Desde luego, en general para la realización de la indagación hermenéutica comprensiva, diatopica y ecosófica se pasan por niveles que están profundamente 
relacionados estos son: los planteados por Santos (2003) analítico, empírico y propositivo; o, los de Ricoeur (1965), semántico, reflexivo y ontológico.

En el caso de Santos (2003) en el primer momento se interpretará y teorizará el devenir de la problemática que se estudia, extrayendo las ideas fuerzas de las obras de los diferentes autores de la investigación y categorías intervinientes; más aun revisando la epistemología de dicha problemática. El segundo momento: el empírico, estará enfocado a interpretar la complejidad de las categorías y el devenir y de la epistemología de esta, en su modo de concebirse, y en especial de cómo se ha llevado a la práctica. La investigadora realizará énfasis en el pensamiento de varios autores confrontando su pensamiento con el de los diferentes autores revisados. El tercer momento se encauzará a la prefiguración del objeto de estudio, para el fortalecimiento de este se desprende de los autores y va a buscar un discurso propio de construcción, donde reconstruye y construye y se sustenta el turismo cultural desde la Educación Patrimonial Transcompleja. Los dos primeros momentos de han cumplido hasta acá y en los dos Rizomas que vienen se tiene el momento propositivo.

\section{RIZOMA PROPOSITIVO: EL PATRIMONIO CULTURAL VISIONADO DESDE LA EDUCACIÓN PATRIMONIAL TRANSCOMPLEJA}

Venezuela se identifica por sus extensas y variadas bellezas naturales, por la diversidad de lugares y monumentos históricos, sus expresiones socioculturales y por su extensa dimensión territorial y complejidad de zonas climáticas, entre otros patrimonios culturales, históricos, ambientales y artísticos, lo que favorecen la práctica del turismo cultural que se ha desarrollado a gran escala en el mundo.

En el turismo cultural debe intervenir el abrazo de los saberes soterrados y los científicos y el papel del ciudadano debe ser propicio para una reconstrucción de su identidad desde el patrimonio natural; lo nuestro auténticamente preservado en medio del hábitat al que pertenece. La riqueza del patrimonio natural, desde el patrimonio histórico es digno de investigar en todos los aborígenes en el país y ser mostrado a turistas del mundo entero. Su importancia ha sido encubierta, por ejemplo en la tribu Warao, pueblo indígena situado en el Delta del Orinoco, uno de los ríos más importantes de América Latina y que en su mayor parte transcurre por Venezuela, la antigüedad de ellos en el Delta del Orinoco es difícil de establecer exactamente, pero los últimos estudios, basados en piezas de cerámica, afirman que sus orígenes se remontan a 17.000 años antes de nuestro Señor Jesucristo.

Con estos datos anteriores, todo parece indicar que esta tribu, la Warao, es las más antigua del Delta y de Venezuela. El término Warao traducido al castellano significa gente de las canoas. Allí hay una riqueza inconmensurable digna de indagar y recrear en su patrimonio natural, y también cultural. De todo ello debe estar impregnado el docente, a fin de ejercer acciones de salvaguarda y transmitirlo en los discentes en la formación en turismo cultural, patrimonio cultural y natural.

Desde la postura transcompleja, puede hacerse realidad en la formación y práctica de una ciudadanía hacedora de cultura y con una identidad de lo nuestro, valorizada e identificada con los orígenes, con el patrimonio natural, con la vida, con el planeta tierra, una Venezuela llena de cultura ancestral, plena de 
biodiversidad y de diversidad cultural; cuenta este hermoso país con más de 115 tepuyes en la Gran Sabana del sureste, el pulmón vegetal más grande del mundo; Auyantepui es el más alto con $700 \mathrm{Km}^{2}$, desde donde se desprende el Salto Ángel la casca más alta del mundo.

En especial, el Parque Nacional Canaima, patrimonio de la humanidad que cubre una superficie inmensa de naturaleza virgen, donde se encuentran las primeras formaciones del planeta tierra. La biodiversidad extraordinaria de animales que cubren llanos, montañas, el Rio Orinoco que nace de un tepuy; es uno de los ríos más largos del mundo. El Estado Amazonas posee la mayor diversidad del planeta protegiendo a la flora y la fauna aún cuidadas bajo la conciencia de nuestros aborígenes descendientes de los Caribes, que conservan casi intacta la pureza de su raza étnica. Dicho estado tiene 8000 especies de plantas, muchas ni siquiera conocidas e infinidad de orquídeas; con una flora y fauna inigualable.

En particular, para los aborígenes Piaroas y Hiwi el Tepuy enmarcado en el Monumento Nacional Cerro Autana constituye una montaña sagrada conocida como Árbol de la Vida, tiene una de las cuevas más antiguas del mundo; formada sólo por cuarcitas que de manera de túnel que atraviesan la montaña completamente, y ésta mide 400 metros de longitud y 54 metros de altura.

Estamos a tiempo de valorar la auténtica riqueza de nuestra cultura y naturaleza desde un turismo cultural profundamente antropoético y ecosófico; con políticas conscientes de lo nuestro. Somos un gran país regalo de DIOS inmenso y amado. Como fotógrafa no puedo desaprovechar la oportunidad de manifestar que amo mi país inmensamente y lo muestro, entre otras acciones, desde el lente de mi cámara, imágenes que pueden ver en la página: https://plus.google. com/+MIBELLAVENEZUELA/

En Rodríguez (2018), en Venezuela, por ejemplo, se muestra como con la fotografía se contribuye al turismo cultural que también sea un turismo sustentable porque presta mayor atención a la vulnerabilidad del medio ambiente del Parque Nacional Mochima, es decir, a los impactos negativos ocasionados por el turismo y la urgencia de considerar en el desarrollo turístico la preservación de los recursos naturales y culturales en todo momento. Es desde la contemplación de la belleza en imágenes la toma de conciencia de un comportamiento ético consciente y pleno a la hora de visitar tan mágico lugar; desde luego posibilitando su conservación y preservación, promoviendo una mejora significativa de los entornos de existencia de la población de Mochima, y buscando el bienestar de los turistas; siempre con la máxima de que el ecosistema no debe afectarse ante tanta belleza del patrimonio natural.

De la reglamentación y legalidad en el aspecto cultural y turístico, la Constitución de la República Bolivariana de Venezuela (Venezuela, p. 183), en el Título VI del Sistema Socio-económico, Capítulo I, Artículo 310, destaca la importancia del turismo y el rol del Estado en su orientación y desarrollo: "El Turismo es una actividad económica de interés nacional prioritaria para el país en su estrategia de diversificación y desarrollo sostenible. Dentro de las fundamentaciones de régimen socio-económico, previsto en esta Constitución el Estado dictará las medidas que garanticen su desarrollo. El estado velará por la creación y fortalecimiento del Sistema Turístico Nacional".

Se expresa en la Ley Orgánica del Turismo (Venezuela, 2012, p.2) que la "cooperación de las comunidades organizadas en instancias del poder popular y demás 
formas de participación, en concordancia con los lineamientos dictados por el Ministerio del Poder Popular con competencia en turismo, así como destinar recursos financieros para tal fin", debe ser prioridad y actualmente cobra preeminencia.

De igual manera la Ley Orgánica del Turismo (Venezuela, 2012), en sus Artículos 99 y 100 plantean promover el desarrollo de la actividad turística con el resguardo del medio ambiente, exigiendo adicionalmente a los prestadores de servicios y turistas la protección y respeto por las manifestaciones culturales, populares, tradicionales y las formas de vida de la población.

Planteamientos similares sobre medidas proteccionistas y de resguardo, se recogen en la Constitución de la República Bolivariana de Venezuela (Venezuela, 1999) cuando expresa en su Artículo 99 que "los valores de la cultura constituyen un bien irrenunciable del pueblo venezolano y un derecho fundamental que el estado fomentará y garantizará procurando las condiciones, instrumentos legales, medios y presupuestos necesario" y "el Estado garantizará la protección y preservación, enriquecimiento, conservación y restauración del patrimonio cultural tangible e intangible y la memoria histórica de la Nación", siendo estos bienes nacionales "inalienables, imprescriptibles e inembargables".

Pese a la legalidad establecida en materia de turismo y cultura, Trejo y Marcano (2016, p.225) afirma que en Venezuela es "necesario determinar que el desarrollo futuro de la región debe ser sostenible y debe contemplar la fragilidad y la biodiversidad de sus ecosistemas y el papel de los recursos naturales debe ser crucial en la generación de múltiples servicios ambientales", como las áreas agrícolas, la belleza de sus paisajes y sobre todo las riquezas y manifestaciones culturales. Se debe incentivar la prácticas en el turismo cultural de del turismo ecológico y el geoturismo que están íntimamente relacionado, a fin de aprovechar la visión de desarrollo sostenible y protección del patrimonio no sólo cultural sino biótico y abiótico en Venezuela, como una estrategia para que las comunidades organizadas puedan diversificar su economía, realizando sus prácticas tradicionales, evitando el abandono de su territorio, generando en la comunidad y en los turistas el uso y aprovechamiento adecuado de los recursos, la salvaguarda de los recursos y patrimonios permitiendo y fomentando la sostenibilidad de la actividad geoturística en el área.

La posibilidad de la Educación Patrimonial Transcompleja es viable en espacios transmodernos aportan escenarios descolonizados para la valorización de nuestra cultura a través, por ejemplo, del turismo cultural como un eje enriquecedor y posibilidad de la toma de conciencia de nuestro valor como país y la salvaguarda de nuestra riqueza cultural autóctona, el patrimonio natural e histórico y la posibilidad de explorar nuestra cultura autóctona y originaria que queda olvidada y relegada en el turismo cultural actual, con excepción en zonas conocidas de nuestro país. Para hacer posible la reforma de la enseñanza y el pensamiento tendente a una Educación Patrimonial Transcompleja, y contribuir con ella a la metamorfosis de nuestro país desde escenarios culturales, necesitamos formar formadores que conozcan el pensamiento complejo, comprendan y desarrollen habilidades para investigar, y se constituyan en comunidad, en grupos transdiciplinares donde los saberes soterrados y científicos se abracen y se posible de compartir en el turismo cultural.

Es improrrogable la atención a las condiciones que se producen por desconocimiento, ligereza, anticientificismo, debilidades conformativas, críticas a la praxis y 
falta de contextualización del pensamiento complejo, de la transcomplejidad como imposibilidad de pensar dentro del pensamiento modernista; la negación de los tradicionalistas a innovar y pensar complejamente; que aquejan a una gran parte de los educadores, maestros, profesores que se acercan al estudio del pensamiento complejo en el área de formación en patrimonio cultural y turismo cultural; razones por las cuales se dedica el turismo cultural a la visita de sitios históricos provenientes de las imposiciones culturales de la invasión al continente en 1492.

Es de reconocer que con la transmodernidad, pensamientos descolonizadores valorizantes de nuestra cultura, una vez más en el ánimo de quienes nos lean, hacedores de la Educación Patrimonial Transcompleja entiendan que sin resentimientos ni aversión alguna contra nadie, ni siquiera contra los compatriotas de nuestros antiguos y actuales colonizadores, debemos estar y creo que sí estamos conscientes de que ninguno, ninguno más que nosotros, ninguno como nosotros, los que nos formamos en nuestra amada Venezuela, estamos en capacidad o condiciones de conocer complejamente, comprender, interpretar y, cuando sea necesario, cambiar o transformar nuestras propias realidades en beneficio de todos los habitantes de esta parte del mundo y atendiendo a su diversidad cultural, su salvaguarda. La turismo cultural es un camino un andar, una filosofía de vida de los que emergemos en nuestro propio país y visitantes que con respeto incursionan en nuestra cultura y hacer.

En espacios transmodernistas donde la postura transcompleja puede hacerse realidad en la formación y práctica de una ciudadanía hacedora de cultura y con una identidad de lo nuestro, valorizada e identificada con los orígenes, con el patrimonio natural, con la vida, una Venezuela llena de cultura ancestral, plena de biodiversidad y de diversidad cultural, donde el multiculturalismo no alcanza el abrazo y el respeto por las culturas. El colonizador intentara imponer su cultura como superior. Rompamos con ello desde lo nuestro y lo que somos con orgullo. En la muestra de nuestra verdadera identidad en un gran país.

El abrazo de los saberes soterrados y científicos es de importancia capital, pues la regularización errada de la cultura en la cientificidad mata o destruye la esencia misma de nuestra cultura, de nuestros originarios. Así como la Educación Patrimonial la concebimos en las aulas de clase, en las instituciones educativas. El aula mente social en la ciudad en pleno, es el hábitat popular, es la cultura en pleno disfrute en cada sitio; es la educación educadora de la que Paulo Freire que con el turismo cultural hace referencia que nos hace abrazar los saberes patrimoniales.

Sin resquemor debemos volver a nuestros orígenes y al cuidado y salvaguarda del patrimonio cultural de nuestros aborígenes; ese reconocimiento le da legitimidad a la Educación Patrimonial Transcompleja; no se trata de una imposibilidad; es que el origen de Venezuela, la Venezuela del Aby Ayala, el continente, no es el país luego que lo masacraron en una invasión; y luego en una colonización del saber y colonialidad del poder. Somos actualmente una mezcla de raza; por la inevitable mezcla que nos impusieron. Pero, nuestra diversidad cultural marca un origen y es menester el reconocimiento desde el turismo cultural. Para ello debemos formar comunidades educadoras y que transformándose en materia de turismo cultural puedan ampliar el aula mente social hacia la Venezuela educadora que le muestra al extranjero, al visitante su gran país haciéndole sentir como en casa. Por algo tenemos comunidades enteras en nuestro país que en un paseo de turista decidieron pernotar para siempre y hacer vida en este país. 
Por otro lado, los ambientes de aprendizaje de la Educación Patrimonial Transcompleja, tales como la lúdica en los museos temáticos venezolanos, en las ciudades urbanas, pero también en lugares de nuestro patrimonio natural, como las zonas indígenas, los habitas populares de las ciudades son recursos ricos que cada día ha venido tomando mayor importancia en los ambientes educativos y en la Educación Patrimonial Transcompleja, en especial acá las Nuevas Tecnologías de la Información y Comunicación hacen un papel importante para promover dichos ambientes. Es necesario que el cultor se encuentre ejerciendo y promoviendo sus manifestaciones con nuestros niños, adolescentes. Esto haría posible el turismo cultural sustentable y sostenible por excelencia para colaborar en la economía de las diversas regiones. Pero sin duda hay que formarse para ello.

Para promover una educación en turismo cultural es necesario el dialogo transdiciplinario enriquece grandemente los ambientes de aprendizaje de la Educación Patrimonial Transcompleja los saberes tradicionales de las ciencias debaten abiertamente con la experiencia acumulada en las personas y organizaciones sociales en su cultura. Es un dialogo que puede promover en las universidades la salvaguarda de nuestra cultura, su conocimiento; una ciudadanía activa. El reconocimiento en la responsabilidad por la destrucción de la tierra y la reflexión sobre la vida, esa responsabilidad antropoetica de la ciudadanía permite pensar en estrategias para el cuidado de la vida y del planeta; haciendo turismo cultural.

Acá la propuesta de descolonizar los patrimonios culturales reconocidos actualmente no significa que ellos dejen de ser lo que son; por ejemplo el Castillo San Antonio de la Eminencia en Cumaná primogénita del Continente Americano fue construido con motivos estratégicos para las batallas entre europeos por nuestro territorio, y en sus cárceles estuvieron encerrados muchos de nuestros libertadores. El realizar obras de teatros donde se ilustren tales realidades podría ser de gran utilidad en una muestra que con el turismo cultural pueda aportar ricamente. Pero también desde la geometría elemental se puede estudiar la forma de dicho castillo y desde la física se puede estudiar mucho de sus materiales y porque en aquel entonces fueron los que se usaron, como los esclavos de la época tenían el ingenio para hacerlo.

Acciones como la que en el año 2016 se realizó con la finalidad de promover una cultura patrimonial en la Escuela Experimental Venezuela el taller de conciencia patrimonial y cultural, con el Ministerio del Poder Popular Para la Educación y del Ministerio Poder Popular para el Turismo. Actividades como esta deben ser cotidiana en las escuelas, no como una actividad extracurricular; sino aquella que en su preparación amena con nuestros patrimonios vivientes se pueda ir llevando ese poder difuso transcomplejo que la Educación Patrimonial Transcompleja debe tener, en miras al proceso de descolonización.

En general en Venezuela la revalorización de los bienes patrimoniales, mostrados desde luego en el turismo cultural no debe circunscribirse a aquellos elementos que tradicionalmente se consideran símbolos de la identidad nacional, tal como ocurre con los museos, monumentos, zonas arqueológicas y centros históricos generalmente construidos con la invasión al continente, sino que se deben incluir elementos de la cultura viva como las artes de artistas contemporáneos y las expresiones populares que son también fuente de expresiones culturales de especial valor, como los tejidos, el hábitat popular, los bailes, los patrimonios vivientes. La cultura contada en vivo por sus patrimonios vivientes. 
De esta manera se le regresa a las comunidades su derecho a ser educadoras de su propias vivencias, este es un elemento que garantiza los derechos de las colectividades al disfrute de su propia cultura. Contrariamente a lo que se ha venido haciendo en turismo cultural no sólo se práctica en los grandes museos, la naturaleza, con lo histórico, lo cultural, las prácticas en el sitio, lo viviente y la belleza de lo autóctono se mezclan en un turismo de excelencia. Es importante crear estas condiciones, y formar gestores para ello. Ejemplo de ello México, pese a ser uno de los países más inseguros se práctica un turismo cultural de excelencia, que ha conseguido su acomodo y seguridad a los turistas en sus buenas políticas y el orgullo por su gran cultura.

Es de hacer notar que el enriquecimiento de las ciencias con la cultural, el hábitat popular es de vital importancia, es de hacer notar que con la transdiciplinariedad pudiéramos estar en la presencia de nuevos conocimientos desde patrimonios locales en la formación en turismo cultural en las Universidades venezolanas; se trata de herramientas epistemológicas y metodológicas que complejamente abren un abanico de posibilidades de estudio y de nuevas profesiones y carreras acorde al momento del país; por ejemplo en un renovado profesional especializado en turismo cultural. Se redimensiona el uso con conciencia y pertinencia de las ciencias; al mismo tiempo que se hace trascender la Educación Universitaria con una visión humana ante los ciudadanos y viva ante la vida cultural-social y activa de la vida de las ciudades, pueblos en general.

De la gestión del turismo cultural se propone la gestión transcompleja del gestor que éste desarrolle actividades con la cultura como: informar, comunicar, crear estrategias, fomentar el aprendizaje, el cambio, adaptación y la transversalidad de la cultura y patrimonio cultural con todas las áreas del conocimiento. Éste gestor debe saber que las comunidades que conviven manifestando la cultural y tienen el derecho y el conocimiento de éste para apoyar en la gestión, conservación y el cuidado de sus bienes culturales. Así como el rescate de patrimonios culturales en los saberes locales, soterrados olvidados, sin valor desvirtuados de los intereses de los seres humanos. Todas estas ideas sobre la gestión son expresadas en Rodríguez (2017b).

El gestor del turismo cultural debe ir a una toma de conciencia colectiva del tipo cultural que valla al rescate de la herencia histórica y esto sólo es posible desde la descolonización, debe mostrarse y promover la conciencia y el orgullo por nuestra cultura autóctona, y el respeto hacia ella del visitante. Pues dicho actividad turística va a develar lo nuestro, lo autóctono y su valorización. Más aún su salvaguarda; se trata de minimizar las consecuencias de un turismo depredador que no deja aportes económicos a los habitantes de la zona visitada y más aún el daño a los patrimonios culturales y naturales.

En suma, la formación de un promotor de nuestra cultura a través de la Educación Patrimonial Transcompleja propende un ser solidario, atropoético, que este abierto a los cambios e innovaciones con mente dinámica requiere de la deconstrucción de la concepción tradicionalista del turismo cultural para poner en escena una renovada, integral, inclusiva, transcompleja que mire la complejidad del turismo cultural en su totalidad, en general la educación patria transcompleja presente en los promotores y ciudadanos intervinientes todos en el turismo cultural y la atención a los visitantes. 
Un gestor transcomplejo para promover el rescate de nuestra valiosa herencia histórica debe ser talante de una educación patrimonial, que no sólo se de en las instituciones educativas, sino en donde se lleve la gerencia, en los sitos del patrimonio cultural, en las comunidades. Debe ser un comunicador por excelencia que promueva saberes del patrimonio descolonizados. ebe estar consciente y promover que no fuimos descubiertos; ni colonizados; sino sometidos, exterminados por millones, destruyendo parte de nuestro patrimonio cultural, la gran diversidad de formas de vida, de pensamiento, de modos de comprensión, de ideas sobre el espacio y el tiempo, de sentidos de la existencia, entre otros, que tenían o siguen teniendo. Es menester una conciencia antropoética, el ejercicio ciudadano de la triada Moriniana: individuo-sociedad y especie.

En general, de acuerdo con Forero (2007) de las bases de la transcomplejidad, las ciencias de la complejidad, el estudio de sistemas socio-naturales y la compresión dialógica, transdisciplinaria de los fenómenos que envuelven la sociedad y el medio ambiente, podrán contribuir a la consolidación de un nuevo orden, un nuevo equilibrio, una construcción ambientalmente sustentable, un reencantamiento del mundo.

En cuanto al turismo cultural en el momento histórico que vive Venezuela visionado desde la Educación Patrimonial Transcompleja es importante clarificar que el proyecto transmoderno en el que se da la creación de la EPT debe dar elementos para educar en patrimonio cultural desde el hábitat cultural, desde la descolonización de las mentes. Para ello no basta con conocer la cultura actual sino realizar una introyección en la formación en patrimonio cultural de las nuevas generaciones de especialistas; que propendan investigar y develar el verdadero potencial cultural de nuestras regiones.

Para ello, la descolonización de las mentes es esencial como el paso para el reconocimiento del hacer en materia de turismo cultural. En primer lugar el hacedor de turismo cultural debe ser un sujeto transmoderno, aquel con el pensamiento del Sur, para ello es necesario e imperante la concepción compleja del pensamiento de lo que significa lo nuestro, esto porque Morín (1998, p. 216) "el pensamiento necesita reflexión (conciencia) y la conciencia necesita pensamiento. Las actividades superiores del espíritu son una constelación de instancias que se producen unas a otras en un bucle recursivo". Por ello el pensamiento complejo está lleno de la concientización que lo hace distintivo en el accionar.

El pensamiento transmoderno bajo el erige de la conciencia re-significada va a la necesidad urgente de develarnos quienes somos, nuestras potencialidades. Pero también, de la destrucción del ambiente, de las guerras, de la negación de nuestros aborígenes; y con ello de la supremacía cultural, denominando las culturas nuestras como minoritarias. Va a una reconstrucción en la educación de una emergencia constitutiva del amor por la vida, por los congéneres, del respeto por el planeta. Es una construcción ecosófica, el arte de habitar en el planeta; con el otro negado, con el olvidado; que es la conjunción de las tres ecologías, la social, espiritual y ecológica; en los estudios de unos de los pioneros Raimon Panikkar y Félix Guattari y otros filósofos humanistas como Rigoberto Pupo que unen la filosofía, el arte, la ciencia y toda producción humana a la tierra, deviene la ecosofía, a una nueva inteligencia del oikos, la casa del mundo y a una renovación práctica del ethos, los modos de habitar.

Para ello el turismo cultural desde la Educación Patrimonial Transcompleja debe tener la conciencia del cuidado de la tierra, de la naturaleza, la salvaguarda de nuestro patrimonio cultural. Y de una conciencia educativa de cómo hacer 
turismo, evitando la depredación, el daño ecológico. Cuestión muy cuestionada últimamente en Venezuela donde grandes patrimonio naturales son destruidos mientras se reconocen otros patrimonios culturales; el genocidio en el Amazonas la destrucción en la extracción de minerales, la destrucción de ríos donde quedan aborígenes sin su hábitat, y esto produce la migración desde sus viviendas.

Volver a juntar lo separado, re-ligar como práctica emergente debe incitar a otra forma de accionar y con-formarse, en un ciudadano transmoderno, dialogante, no excluyente, consciente de su papel en la historia, especialmente la del Sur; Morín y Kern (1993, p.117) afirma que "habría necesidad de una ciudadanía planetaria, de una conciencia cívica planetaria, de una la opinión intelectual y científica planetaria, de una opinión política planetaria".

Para lograr tal fin, la educación nuestra autentica descolonizada, cargada de un poder suave de renovación de nuestros saberes aborígenes, cotidianos, autóctonos, descolonizados es urgente; ecologizados con los conocimientos científicos, operados por las pedagogías decoloniales que de acuerdo con Walsh (2014, p.15) "serían ellas construidas y por construir: en escuelas, colegios, universidades, en el seno de las organizaciones, en los barrios, comunidades, movimientos y en la calle, entre otros lugares".

Es una educación en materia de turismo cultural re-significada y re-significante de lo nuestro, de lo olvidados, fuera de las elites colonizadoras disyuntivas y unidisciplinarias; González (2013, p.167) afirma que "es necesario que la educación logre penetrar en lo más íntimo del ser humano "su conciencia" y que la visión de mundo y universo logren generar una existencia basada en el amor y la libertad del sujeto". Excelsitudes como religar lo científico con lo cotidiano, la persona con la naturaleza, la vida en general que no existen separada de la tierra.

\section{RIZOMA: CONCLUSIONES, QUE MÁS BIEN SON UN COMIENZO}

El turismo cultural sustentado desdela Educación Patrimonial Transcomplejidad constituye un espacio político donde desde la diversidad cultural como el patrimonio cultural universal se establece relaciones de reconocimientos de los países y con ello el respeto por los ciudadanos. Desde acá el turismo cultural debe constituir un espacio para un diálogo fecundo desde la conciencia de la mutua diferencia, sin políticas de sometimientos y el reconocimiento que pertenecemos a la misma tierra a la que debemos salvaguardar; las fronteras son sólo eso.

En Venezuela, es deseable la conformación de un sujeto transmoderno en materia de turismo cultural que conyugue a la protección de nuestra cultura, el patrimonio cultural y natural, su salvaguarda; si sometimiento, liberado de las opresiones politiqueras en favor de intereses particulares; ir a un verdadero ejercicio educativo patrimonial en material de una gestión transmoderna y transcompleja.

Como la Educación Patrimonial Transcompleja es el ejercicio educativo que tiene por base el asunto patrimonial que es esencialmente política y se muestra como un dinámico elemento de ciudadanía e inclusión social de la cultura autóctona y desde el turismo cultural cobra preeminencia de excelencia; favoreciendo a los pueblos económicamente y dándole la importancia que merecen. Donde los espacios de independencia y autodeterminación venezolano están en consonancia con su cultura; ejercicio educativo que es atravesado pon la cotidianidad y los saberes 
soterrados; la historicidad en la Educación Patrimonial Transcompleja forma parte de la vida del ciudadano y la conformación de su identidad; hacia la defensa del patrimonio más universal: la tierra. De acá que la ecosofia, el arte de habitar en el planeta, es altamente relevante en ese individuo, ciudadano antropoetica pues esta empoderado de la sabiduría para habitar su país.

La Educación Patrimonial Transcompleja se configura como un proceso dinámico, emergente, religante y relativo donde se complejiza el patrimonio cultural desde aprender, desaprender y reaprender siguiendo las huellas de los saberes patrimoniales en el turismo cultural. Es así como el contexto de los discursos y las prácticas en el día a día del turismo cultural se realizan con las mentes descolonizadas de los docentes, del ciudadano, del habitante de las comunidades, del aborigen. El desarrollo de la nación va en consonancia en este sentido con las buenas prácticas del turismo cultural y sus políticas educativas patrimoniales. Por ello la Educación Patrimonial Transcompleja como alfabetizadora del ciudadano tiene mucho sentido. Se cuentan con muchos profesionales analfabetos culturalmente; practicantes transculturizados que desvalorizan nuestra cultura.

Finalmente, el ejercicio del turismo cultural sustentado en la Educación Patrimonial Transcompleja, se caracteriza porque que se requiere del trabajo complejizado de diálogos y acuerdos en conjunto entre los diversos actores de los sectores turísticos y culturales, los cultores de las comunidades locales que mediante adecuados procesos de gestión transcompleja, produzcan desarrollos turísticos sanos y equilibrados, atractivos y portadores de políticas comprometidas y una continua formación de gestores culturales.

\section{REFERENCIAS}

Abreu, J., \& Lunar, R. (2008). Incorporación del patrimonio ambiental de la Parroquia Chuao, a la oferta turística del Estado Aragua, Venezuela. Gestión Turística, 9, 37-59.

Balza, A. (2016). Filosofía e investigación educativa desde la transcomplejidad. En: Investigación transcompleja. Génesis, avances y prospectivas. Caracas: Red de Investigadores de la transcomplejidad REDIT.

Campodónico, R., \& Chalar, L. (2013). El turismo como construcción social: Un enfoque epistemo-metodológico. Anuario Turismo y Sociedad, 19, 47-63.

Deleuze, G., \& Guattari, F. (1994). Mil mesetas. Valencia: Editorial pre-textos.

Dussel, E. (1992). La ética de la liberación: ante el desafío de Opel, Taylor y Vatio con respuesta crítica inédita de K.-O. México: Opel.

Forero, E. (2007). Turismo cultural: Patrimonio, identidad, territorios y sustentabilidad una mirada desde las ciencias de la complejidad. Revista EAN, 60,165-182.

García, Z. (2016). ¿Cómo impedir la muerte social del patrimonio cultural? Educación Patrimonial un área emergente. MOUSEION, 23, 41-56.

González, J. (2010). Teoría Educativa Trans-compleja. La Paz: Edición La Paz: IIICAB.

González, J. (2013). Aula mente social. Pensamiento transcomplejo Tomo III. Barranquilla: Universidad Simón Bolívar.

Luzardo, M. (2014). Potencialidades y estrategias para la puesta en valor turístico del frente de agua y casco histórico de los Puertos de Altagracia (Venezuela). Tesis del Doctorado en gestión y desarrollo turístico sostenible. Universidad de Málaga. Málaga, España. 
Moreno, H. (2016). La concepción de los Patrimonios Culturales y Naturales desde el Pensamiento Complejo. Maestría en Investigación Integrativa. Multiversidad Mundo Real Edgar Morín, A.C. México.

Morín, E., \& Kern, A. (1993). Tierra Patria. Editorial Nueva Visión. Buenos Aires.

Morín, E. (1998). Introducción al pensamiento complejo. Madrid: Gedisa.

Muñoz, F. (2014). La epistemología y el turismo, Anuario Turismo y Sociedad, XV, 187-203. DOI: 10.18601/01207555.n15.11

Nava, C., \& Castillo, M. (2017). Actualidad de la teoría crítica en los estudios del turismo. Turismo y Sociedad, XX, pp. 49-74. DOI: https://doi.org/10.18601/01207555.n20.03

Pupo, R. (2014). La educación, crisis paradigmática y sus mediaciones. Sophia, Colección de Filosofía de la Educación, 17, 101-119.

Pupo, R. (2017). La cultura y su aprehensión ecosófica. Una visión ecosófica de la cultura. Alemania: Editorial Académica Española.

Ricoeur, P. (1965). Hermenéutica de los símbolos y reflexión filosófica. Santiago de Chile: Universidad de Chile.

Rodríguez, M. (2017a). Fundamentos epistemológicos de la relación patrimonio cultural, identidad y ciudadanía: hacia una Educación Patrimonial transcompleja en la ciudad. (Tesis Doctoral. Universidad Latinoamericana y el Caribe). Caracas, Venezuela.

Rodríguez, M. (2017b). Deconstrucción de la gestión del patrimonio cultural en la modernidad: Su gestión transcompleja en la transmodernidad. Revista Digital de Gestión Cultural, 12, 4-17.

Rodríguez, M. (2018). La Educación Patrimonial y la formación docente desde la transcomplejidad. TELOS. Revista de Estudios Interdisciplinarios en Ciencias Sociales, 20(3), 431-449.

Santos, B. (1998). Por una concepción multicultural de los derechos humanos. México: Universidad nacional Autónoma de México.

Santos, B. (2002). Hacia una concepción multicultural de los derechos humanos. EL OTRO DERECHO, 28, 59-83.

Santos, B. (2003). Crítica de la Razón Indolente Contra el Desperdicio de la Experiencia, Volumen I, Para un Nuevo Sentido Común: La Ciencia, El Derecho y La Política En La Transición Paradigmática. Madrid: Editorial Desclée De Brouwer, S.A.

Trejo, J., \& Marcano, N. (2016). Ecoturismo y Geoturismo: alternativas estratégicas para la promoción del turismo ambiental sustentable venezolano. Revista de Investigación, 40, 202-228.

Venezuela. (1999). Constitución de la República Bolivariana de Venezuela - CRBV. Recuperado de: https://venezuela.justia.com/federales/constitucion-de-la-republicabolivariana-de-venezuela/.

Venezuela. (2012). Ley Orgánica del Turismo. Recuperado de: https://aldiavenezuela. microjuris.com/2012/06/27/decreto-de-ley-organica-del-turismo/

Walsh, C. (2014). Interculturalidad Crítica y Pedagogía Decolonial: Apuestas (des)del InSurgir, Re-existir y Re-vivir. Recuperado de https://www.maxwell.vrac.puc-rio.br/

Recebido em: 21/01/2019

Aprovado em: 18/05/2019

\section{CONTRIBUIÇÃo}

Milagros Elena Rodríguez: Autoria única. 